\title{
INVESTIGATION ON FRACTURE MECHANISMS AND CRACK PROPAGATION PROCESS OF NATURAL ROCK-CONCRETE INTERFACE
}

\author{
WEI. DONG ${ }^{*}$, NA. WANG ${ }^{\dagger}$, ZHIMIN. WU ${ }^{\dagger+}$ AND BOHAN. XU ${ }^{\dagger+}$, \\ State Key Laboratory of Coastal and Offshore Engineering, Dalian University of Technology \\ (DUT) \& Ocean Engineering Joint Research Center of DUT-UWA \\ Dalian CHINA \\ e-mail: dongwei@dlut.edu.cn \\ ${ }^{\dagger}$ Dalian University of Technology (DUT) \\ Dalian CHINA \\ ${ }^{\dagger+}$ Dalian University of Technology (DUT) \\ Dalian CHINA \\ e-mail: wuzhimin@dlut.edu.cn \\ †† \\ Dalian University of Technology (DUT) \\ Dalian CHINA \\ e-mail: bohanxu@dlut.edu.cn
}

Key words: Rock-concrete Interface, Interfacial Fracture, Constitutive Law, Crack Propagation

\begin{abstract}
The tests of uniaxial tension and three-point bending are carried out on rock-concrete composite specimens with natural interfaces to investigate the interface mechanics and fracture process so that to establish interface tension-softening constitutive law between concrete and rock. Tensile strength, fracture energy and initial fracture toughness of rock-concrete interface are investigated qualitatively. Based on the load-displacement curves measured in three-point bending test, the energy dissipation at rock-concrete interface is derived using the modified J-integral method. Further, through enforcing balance between energy dissipation and energy caused by fictitious cohesive force acting on fracture process zone, the tension-softening constitutive law of rock-concrete interface is established, which takes into account the effects of fracture energy and tensile strength of interface. For the sake of practical applications, the tension-softening constitutive expression is simplified as a bilinear function. Finally, the crack propagation process of the concrete-rock composite beam is simulated numerically based on nonlinear fracture mechanics theory by introducing a crack propagation criterion. The predicted P-CMOD curves show a reasonable agreement with the experimental ones, which verifies the tension-softening constitutive law for rock-concrete interface derived in this study.
\end{abstract}

\section{INTRODUCTION}

The interface between the concrete and the rock is usually considered as the weakest link in concrete structure built on rock foundation, e.g. concrete dams. The crack development caused by the hydrostatic load application results in the significant change in the failure resistance of the dam, so that the crack initiate 
and propagate along the interface[1, 2] are concerned by scientific and engineering communities. In fact, the rock-concrete interfacial bond property mainly depends on adhesion between rock and concrete at the interface, cohesion in the substrate concrete, friction, and aggregate interlock [3]. So, the degree of roughness in interface affects the failure performance of the rock-concrete joint. Specially, for the rock with a natural surface in a practical engineering, the fracture properties of rock-concrete interface should be pay more attention since the bond between rock and concrete is not perfect.

The softening constitutive is one of the fracture properties of interface, and is suitable to evaluate the bond failure behavior in the stage of post-peak load. Similar to the cementbased materials, the rock-concrete interface has the quasi-brittle characteristic, i.e. there is a fracture process zone (FPZ) ahead of the interface crack, which can describe its strain softening and strain localization behavior. According to the fictitious crack model proposed by Hillerborg [4], the tension softening characteristic of FPZ in cementbased materials can be described using the normal stress acting on crack surface vs. crack opening displacement. In the case of rockconcrete interface, from the view of exploring rock-concrete interface bond mechanism, it is significant to experimentally study the interfacial fracture behavior and obtain the tension constitutive relationship.

In line with this, the objective of this paper focuses on the rock-concrete interface fracture properties and tension softening constitutive model subject to mode I fracture. Experimental studies are carried out to investigate the interfacial fracture toughness, fracture energy and bond strength with respective to the rock-concrete natural interfaces. A tension softening constitutive model is derived, which takes into account the effects of interfacial fracture energy, tensile strength. Finally, the numerical simulation aiming at the interfacial crack propagation process is conducted to validate the derived tension constitutive model through comparing the $P-C M O D$ curves in numerical and experimental.

\section{EXPERIMENTAL PROGRAM}

The specimens used in this study included the $100 \times 100 \times 100 \mathrm{~mm}^{3}$ prisms and $100 \times 100 \times$ $500 \mathrm{~mm}^{3}$ three-point bending (TPB) beams. The initial cracking ratio $a_{0} / D$ of TPB is varied from 0.2 to 0.6. All specimens consisted of two geometrically identical blocks, which are rock and concrete, respectively. Mix proportion of the concrete for this study was 1:0.62:1.8:4.2 (cement: water: sand: aggregate) by weight, and the maximum aggregate size is $10 \mathrm{~mm}$. The natural surface of rock can be obtained from the three-point bending beam test of rock with/without notch, which was shown in Fig. 1. The measured materials properties of concrete and rock are listed in table 1.

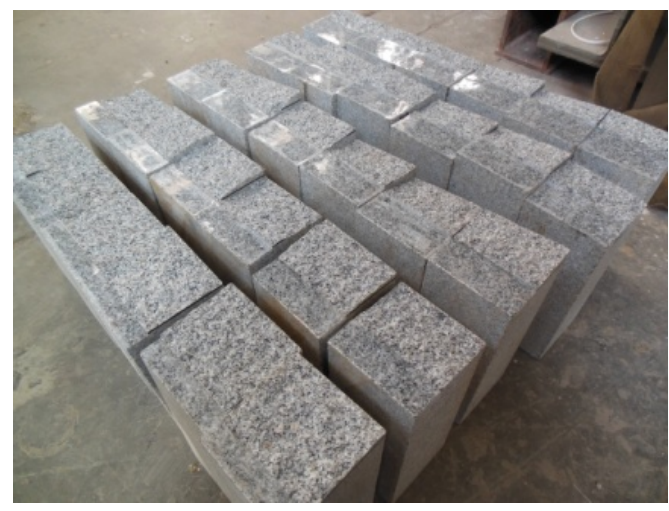

Figure 1: Natural interfaces of rock.

Table 1: Materials properties of rock and concrete

\begin{tabular}{ccccc}
\hline Material & $E_{t}(\mathrm{GPa})$ & $v$ & $f_{\mathrm{c}}(\mathrm{MPa})$ & $f_{t}(\mathrm{MPa})$ \\
\hline Concrete & 30.26 & 0.238 & 36.13 & 2.88 \\
Rock & 64.39 & 0.198 & 119.2 & 8.65 \\
\hline
\end{tabular}

A closed loop servo-controlled testing machine with a capacity of $250 \mathrm{kN}$ was used for the TPB test. The loading-point displacement of composite specimen and crack mouth opening displacement were measured by two clip gauges. In order to obtain the crack tip opening displacement and crack propagation process, four clip gauges were arranged equidistantly from the tip of precrack to the top of the composite beam. To measure the initial load, four stain gauges were 
attached vertically in front of the precast notch on the both sides of specimen, and the distance of two strain gauges was $10 \mathrm{~mm}$. The experimental setup for TPB test is shown in Fig. 2.

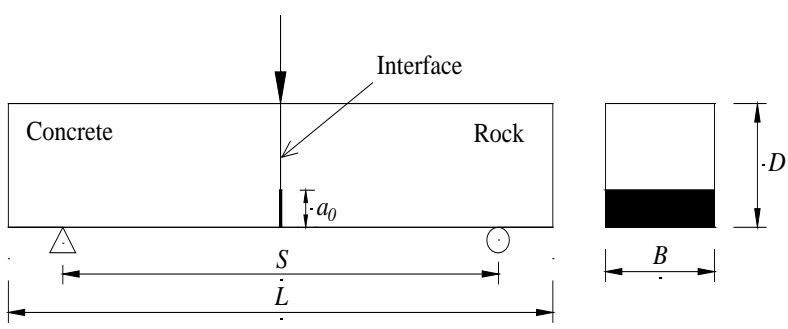

Figure 2: TPB test setup.

The displacement extrapolation method [5] was used to calculate the stress intensity factors (SIFs) $K_{1}$ and $K_{2}$ of bi-materials interface crack through relative crack surface displacements $\delta_{\mathrm{x}}$ and $\delta_{\mathrm{y}}$. It should be noted that stress intensity factors $K_{1}$ and $K_{2}$ can be denoted as $K_{1}^{\mathrm{ini}}$ and $K_{2}^{\mathrm{ini}}$, which are the initial fracture toughness, when $\delta_{\mathrm{x}}$ and $\delta_{\mathrm{y}}$ are caused by initial load.

\section{RESULTS AND DISCUSSIONS}

\subsection{Fracture properties of natural interface}

Figures 3 and 4 illustrate the relationships of peak load $P_{\max }$ and the ratio of $\left|K_{2}^{\text {ini }} / K_{1}^{\text {ini }}\right|$ with initial crack ratios, $a_{0} / D$, respectively. According to the results, $P_{\max }$ deceases with the increase of $a_{0} / D$. Meanwhile, the ratio of $\left|K_{2}^{\text {ini }} / K_{1}^{\text {ini }}\right|$ increases when $a_{0} / D$ varies from 0.2 to 0.6 . However, the maximum of the ratio is lower than 0.1 , which indicates that the rockconcrete interfacial fracture is approximate mode I dominated under TPB loading condition. Moreover, $K_{1}^{\text {ini }}$ does not vary significant with the variation of $a_{0} / D$. So, $K_{1}^{\text {ini }}$ of rock-concrete natural interface can be regarded as being in-dependent on $a_{0} / D$, which is the same conclusion drawn from concrete materials. Comparing with plain concrete used in this study, i.e. $K_{1}^{\text {ini }}=0.49 \mathrm{MPa} \bullet \mathrm{m}^{1 / 2}$ and $G_{f}$ $=87 \mathrm{~N} / \mathrm{m}$, the nature interface shows the low crack resistance and the weak energy absorbing capacity during crack propagation.

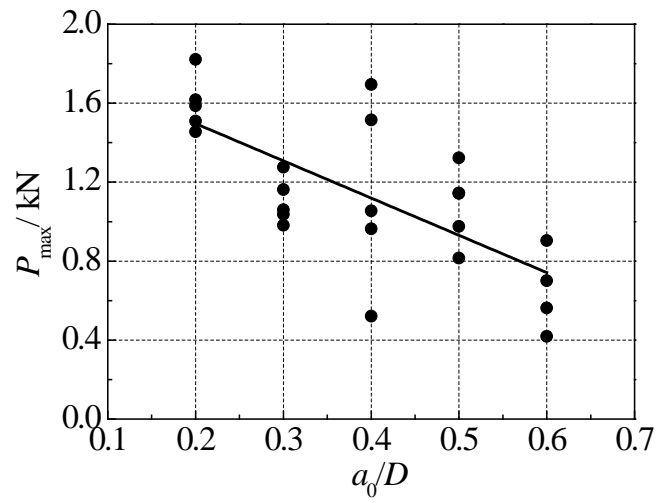

Figure 3: Effect of $a_{0} / D$ to $P_{\max }$

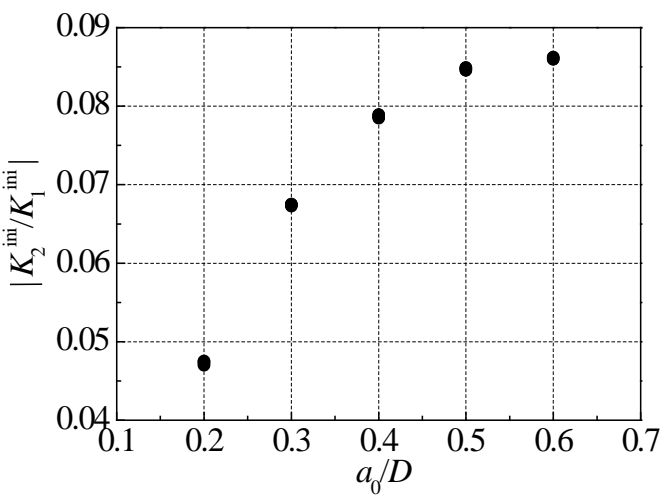

Figure 4: Effect of $a_{0} / D$ to $\left|K_{2}^{\text {ini }} / K_{1}^{\text {ini }}\right|$

\subsection{Tension softening constitutive of rock- concrete interface}

To get the tension-softening diagram after the interfacial peak stress, Niwa et al. [6] proposed a modified J integral method, which can consider crack propagation and remove the elastic displacement of the beam due to the crack initiation. The J-integral is defined as the energy available for crack propagation $E(\delta)$, which can be interpreted as the total absorbed energy of the cracked specimens minus released elastic energy during unload process. If the unloading and reloading path can be assumed to be linear, $E(\delta)$ can be written as:

$$
E(\delta)=\int_{0}^{\delta} P(\delta) d \delta-\frac{1}{2} P(\delta)\left(\delta-\delta_{P}\right)
$$

where $\delta$ is the displacement under a certain load and $\delta_{p}$ is the residual displacement in a fully unloaded state, which can be obtained from unloading and reloading process.

As an example, Figures 5 illustrates the $P-\delta$ 
curves of specimen TPB5-2 with the natural interface, respectively. Based on the operations of unload and reload for all specimens, the experimental $\delta$ - $\delta_{p}$ relationship can be derived through normalizing by the maximum displacement $\delta_{\max }$. Therefore, $\delta$ - $\delta_{p}$ relationship can be formulated as:

$$
\delta_{p} / \delta_{\max }=\left(\delta / \delta_{\max }\right)^{1.375}
$$

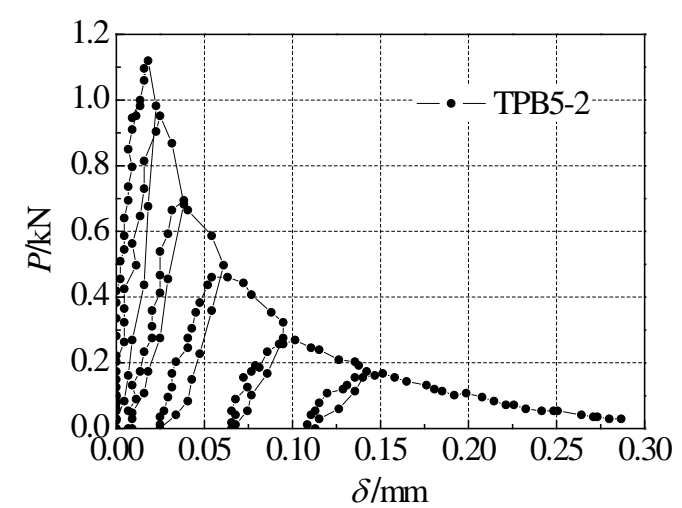

Figure 5: Load-displacement relationship of TPB 5-2

If the energy $E(\delta)$ is used to drive the crack propagation, the tension softening relationship can be derives as:

$$
\sigma(w)=\frac{1}{a b}\left(2 E^{\prime}(w)+w E^{\prime \prime}(w)\right)
$$

where $E^{\prime}(w)$ and $E^{\prime \prime}(w)$ are the first and second derivatives of energy $E, a$ and $b$ are the crack propagated length and beam width, $\sigma$ is the cohesive stress acting on fracture process zone, and $w$ is the crack width. Based on the experimental results, $a-w$ relationship (normalized by the ligament height $a_{\max }$ ) and $a-\delta$ relationship (normalized by the maximum displacement $\delta_{\max }$ ) can formulated as:

$$
\begin{aligned}
& a / a_{\max }=1-\left(1-\sqrt{w / w_{\max }}\right)^{5.76} \\
& a / a_{\max }=1-\left(1-\sqrt{\delta / \delta_{\max }}\right)^{5.48}
\end{aligned}
$$

Through substituting equations (2), (4) and (5) into equation (3), the expression of tension softening constitutive of rock-concrete interface can be obtained, which is shown as:

$$
\begin{aligned}
& \sigma / f_{t}=\left(1-\sqrt{w / w_{0}}\right)^{q} \\
& q=0.385 \cdot f_{t} \cdot w_{0} / G_{f}
\end{aligned}
$$

Further, from the point of view of simplification in practical applications, a bilinear model, defined as four parameters, $f_{t}$, $\sigma_{s}, w_{s}$, and $w_{0}$, is derived to represent the real tension softening constitutive of rock-concrete interface. A bilinear expression of tension softening constitutive is obtained as Equations (8)-(10):

$$
\begin{aligned}
& \sigma_{s}=0.2 f_{t} \\
& w_{s}=0.8 G_{f} / f_{t} \\
& w_{0}=6 G_{f} / f_{t}
\end{aligned}
$$

\section{APPLICATION AND VERIFICATION}

In order to verify the derived tension softening constitutive of rock-concrete interface, the numerical simulation of crack propagation in the rock-concrete interface is carried out to get the $P$-CMOD curves and the FPZ variation. A crack propagation criterion based on initial crack toughness[7, 8] is introduced to determine the crack propagation in rock-concrete interface. This criterion can be described as following: crack begins to propagate when the difference, between the stress intensity factors $K_{1}^{P}$ caused by the applied load and $K_{1}^{\sigma}$ by the cohesive stress, exceeds the initial fracture toughness $K_{1}^{\text {ini }}$ of rock-concrete interface. The details of the iterative process for analyzing crack propagation based on the crack propagation criterion can be found by referring to literature [9]. In this numerical approach, finite element analyses were carried out using ANSYS code to simulate the crack propagation process. In Figure 6, it can be found that the numerical result agrees well with the experimental.

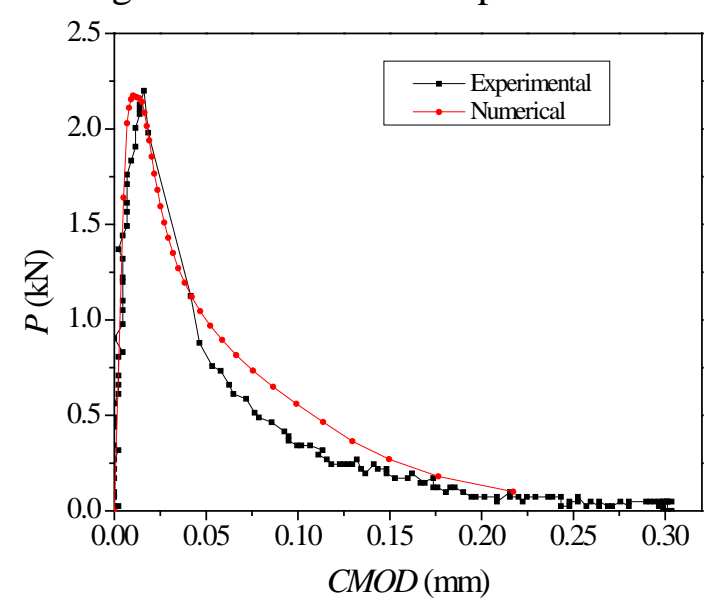

Figure 6: Load-displacement relationship 
Meanwhile, the crack propagation process of a TPB beam was observed through DIC technique. The FPZ evoluation was derived from the experiment and is compared with the numerical results (See Figure 7). The experimantal and numerical results have a well agreement, which suggests that the numerical method, together with the bilinear tension-softening constitutive law derived in this paper, can be used for simulating the complete fracture process in a rock-concrete interface.

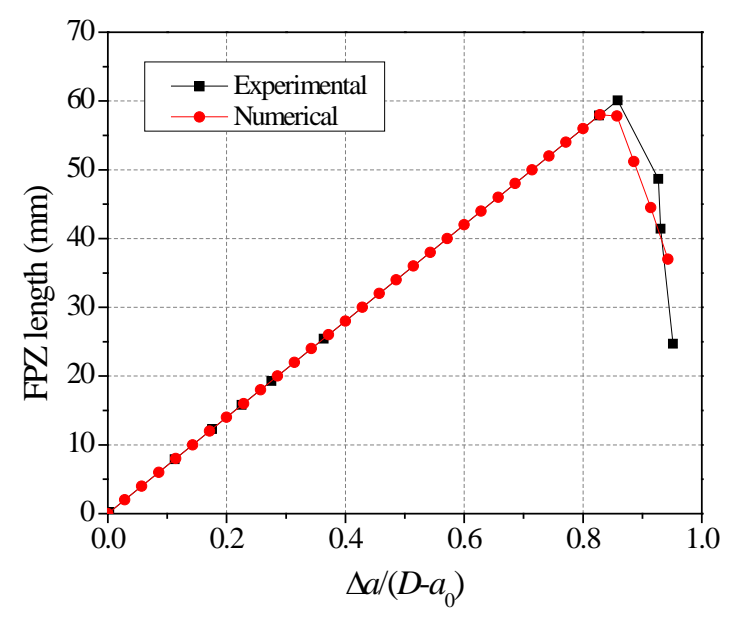

Figure 7: FPZ evolution

\section{CONCLUSIONS}

The experiments of uniaxial tension and three-point bending were carried out for the rock-concrete composite specimens with natural interfaces. According to the experimental results, for the natural interface, initial fracture toughness $K_{1}^{\text {ini }}$ and fracture energy $G_{\mathrm{f}}$ are independent on the initial crack ratio $a_{0} / D$. Meanwhile, the natural interface shows low bond effect. Using the modified Jintegral method, an exponential tension softening constitutive of rock-concrete interface was derived from the experimental results by taking into account of fracture energy, tensile strength and stress-free crack opening displacement. Comparing with the experimental $P$-CMOD curves and FPZ evolution, the numerical results show a reasonable agreement, which indicates that the derived bilinear tension softening constitutive is valid to describe the softening characteristics of rock-concrete interface in the stage of post-peak load.

\section{REFERENCES}

[1] Kishen, J. M. C. and Singh, K. D. 2001. Stress intensity factors based fracture criteria for kinking and branching of interface crack: application to dams. Engineering Fracture Mechanics 68(2): 201-219.

[2] Zhong, H., Ooi, E. T., Song, C., Ding, T., Lin, G. and Li, H. 2014. Experimental and numerical study of the dependency of interface fracture in concrete-rock specimens on mode mixity. Engineering Fracture Mechanics 124-125:287-309.

[3] Zhang, D., Ueda, T. and Furuuchi, H. 2013. Fracture Mechanisms of Polymer Cement Mortar: Concrete Interfaces. Journal of Engineering Mechanics 139(2):167-176.

[4] Hillerborg, A., Modéer, M. and Petersson, P.E. 1976. Analysis of crack formation and crack growth in concrete by means of fracture mechanics and finite elements. Cement and Concrete Research 6(6):773781.

[5] Nagashima, T., Omoto, Y. and Tani, S. (2003) Stress intensity factor analysis of interface cracks using X-FEM. International Journal For Numerical Methods In Engineering 56(8):1151-1173.

[6] Niwa, J., Sumranwanich, T. and Tangtermsirikul, S. 1998. New method to determine tension softening curve of concrete In Fracture Mechanics of Concrete Structures: Proc., FRAMCOS-3. AEDIFICA TIO, Freiburg, Germany, vol. 1, pp. 347-356.

[7] Xu, S. L., Reinhardt, H.W. 1999. Determination of double-Determination of double-K criterion for crack propagation in quasi-brittle fracture Part $\mathrm{I}$ : experimental investigation of crack propagation. International Journal of Fracture 98:111-149.

[8] Xu, S. L., Reinhardt, H.W. Determination of double-K criterion for crack 
propagation in quasi-brittle fracture Part I I: Analytical evaluating and practical measuring methods for three-point bending notched beams. International Journal of Fracture 98:151-177.

[9] Dong, W., Wu, Z. and Zhou, X. 2013. Calculating crack extension resistance of concrete based on a new crack propagation criterion. Construction and Building Materials 38:879-889. 